werde. Dafs aber von dieser Reaction nur unter grofser Beschränkung Gebrauch gemacht werden könne, zeigen folgende Beobachtungen von Davidson.

Bei der Untersuchung des Urins eines Kranken fand er, dafs derselbe nach Zusatz von Jodsäure einen merklichen Geruch nach Jod annahm, und nun durch Amylum eine blaue Farbe erhielt. Bei genauer Untersuchung fand sich, dafs nicht der Harnstoff, sondern die Harnsäure diese Zersetzung der Jodsäure bewirke, und dars sie durch diese Reaction im Harne Gesunder und Kranker wieder erkannt werden könne. Aehnlich wirkt aber auch das Serum des Blutes und alle eiweifshaltigen Flïssigkeiten. Hieraus ergicbt sich, dafs die Jodsäure durch Substanzen rersetzt wird, die in unsern Nahrungsmitteln und in den flüssigen und festen thierischen Theilen reichlich vorhanden sind, und dafs ein Bestandtheil des Urins dieselbe Zersetzung bewirkt. Wenn also bei Vergiftungsfällen mit Morphium oder Opium, die untersuchten Contenta des Magens oder weitere Flüssigkeiten, Eiweifs oder Harnsäure enthalten, so kann die Erkennung des Morphiums durch Jodsäure nur zweifelhaft sein und diese nicht als ein Reagens dafür angeseben werden*).

Vierte Abtheilung.

\title{
Naturgeschichte und Pharma- kognosie.
}

Ueber die Samen von Phytelephas macrocarpa (Rz. et Pav.);

Dr. Müller in Emmerich.

Die Samen dieser Pflanze kommen über England unter dem Namen lvory Not (Elfenbeinnufs) nach Deatschland. Sie sind von der Gröfse einer starken Wallnufs,

*) Journ. de Chim. med. 2. Ser. VI, 320. 
länglichrund, haben eine brännliche Farbe und sind in der Gegend, wo sich der Embryon befindet, etwas plattgedrückt, dabei steinhart. Entfernt man die branne Bedeckung, so hat man eine elfenbeinartige weifse Masse vor sich, welche die schönste Politur annimmt, daher die Samen denn auch von den Drechslern zur Anfertigung von Knöpfen und anderen Arbeiten dienen. Das Innere der Samen besteht nach meiner Untersuchung ganz aus verhärtetem Eiweilsstoff und einer geringen Mengè fetten aber scharfen Oels, welches ich näler untersuchen werde.

Hr. Hofrath Professor von Martius in Mänchen hatte die Güte, bei seiner Anwesenheit zur Zeit der Versammlung deutscher Naturforscher-und Aerzte in Mainz, diese demselben von mir vorgezeigten Samen, als von obiger Pfanze abstammend, za bestimmen, und zugleich zu bemerken, dafs diese Pflanze zwischen den Pandaneae, Typhaceae und Palmae stehe, ersterer Familie wohl am nächsten, und dafs solche in Guatemala und Peru einheimisch sei.

\section{Untersuchung des Copals ; E. Filhol.}

Man theilt den Copal des Handels in harten und weichen. Der harte Copal kommt in mehren, nach ihrem Ursprunge unterschiedenen Varietäten vor. Die hauptsächlichsten sind der von Madagascar und der indische, aus diesen beiden besteht fast aller käufliche Copal und sie werden ausschliefslich znr Firnifsbereitung verwendet. Eine dritte Varietät kommt angeblich aus Brasilien oder ehemals aus Nordafrika, ist seltener und weniger geschätzt, als die beiden ersten. Der Copal von Madagascar bildet gewöhnnlich Stücke von bedeutender Gröfse, besilzt stets eine glat . Oberfläche, während die des indischen immer runzlich ist. Er ist durchsichtig, gleichmä fsig citrongelb, 